\title{
Endorsement of Career and Technical Education: Phenomena Influencing Core-Subject Teacher Perceptions
}

\author{
Sheri Lynn Tucker \& Andrew John Hughes
}

\begin{abstract}
The article provides an analytical overview of core-subject teachers' endorsement of career and technical education (CTE). The article discusses phenomena that have likely influenced core-subject teachers' perceptions of $\mathrm{CTE}$ and, in turn, their endorsement of CTE to students. California is taking steps towards successfully preparing students for college and career readiness, but more needs to be done (Bae \& Darling-Hammond, 2014). Additionally, some educators still believe that "CTE programs maintain diminished value in helping to raise school achievement scores or encourage student success" (Shanklin, 2014, p. 3). Since the 20th century, CTE educators have been fighting negative perceptions of CTE, particularly that the only students who enroll in CTE are disengaged or underperforming. The study had a sample size of 16 participants $(N=16)$, and data were collected using focus groups, one-on-one interviews, and surveys. Findings show that participants were generally unaware of but were still biased against CTE. Participants' biases were influenced by multiple phenomena, including perfectionism, educational reforms, and societal expectations.
\end{abstract}

Keywords: teacher perceptions, career and technical education (CTE), college and career readiness, teacher support, administrative support

Career and technical education (CTE) continues to be perceived by coresubject teachers as well as the general public as a lesser-than, non-college-bound option; an option that is only fit for unmotivated or disinterested students. According to Bartholomew (2014), Gray (2004), Wonacott (2003), and others, the current debate regarding the value of CTE as an integral part of the standard academic curriculum has been ongoing since at least the early 1900s. The general public has a negative perspective of CTE that might be partially based on the blue-collar and white-collar separation seen in early descriptions of vocational and liberal education (Wonacott, 2003). Vocational education is for those wanting to earn a living or be productive in the workplace, whereas liberal education is for those wanting to fit in among others by developing intellectual capacities (Wonacott, 2003). Although these descriptions may have fit at one This study described in this article is based on the first author's dissertation study (Tucker, 2019). 
time, they are no longer viable. However, these perceptions persist based on numerous phenomena that have promoted the idea that CTE is only for noncollege-bound students. For example, there are those who push for a 4-year liberal arts degree as a guarantee of white-collar employment that outweighs the trade-off of student-loan debt. In fall 2018, the graduation rate at California State University, San Bernardino (CSUSB), our local university, was 19\% in 4 years and $57 \%$ in 6 years; therefore, pushing students to attend a 4 -year liberal arts university is not working for the majority of students.

Perceptions of CTE are a common theme in the literature; thus, one might think that phenomena related to negative perceptions of CTE were being adequately addressed throughout the educational system. CTE literature continually presents rationales for including CTE as a part of the academic curriculum, frequently applying the idea that students will see the relevance to academic knowledge when this knowledge is applied in a CTE setting. It is impossible to argue with that rationale because CTE classrooms do provide students with the much-needed opportunity to apply knowledge during practical hands-on learning (Brand, Valent, \& Browning, 2013). Despite CTE's rigorous focus on both academic and industry standards, technological literacy, and the development of 21 st-century skills as well as the growing body of evidence suggesting a variety of benefits, CTE still has critics (Plank, DeLuca, \& Estacion, 2008).

CTE is different today from even what it was just 8 years ago. Yet, critics of CTE continue to uphold long-standing stereotypes: "it prepares students only for work after high school, and its students are mostly male, too often minorities, academically backward, and destined for dead-end jobs" (Gray, 2004, p. 129). These same critics seem to endorse student choices related to differentiated learning, including Advanced Placement and honors programs (Gray, 2004). Despite supporting these choices of differentiation for academically blessed students, critics reject CTE as an important part of the developmental process for all students (Gray, 2004). The negative perceptions held by some in large part may be "because CTE has been chronically neglected by American education leaders and policymakers" (Dougherty, 2016, p. 1). "There was a time when 'vo-tech' was a pathway to nowhere. 'Tracking,' as practiced in the twentieth century, was pernicious. It sent a lot of kids - especially low-income and minority students - into low-paying, menial jobs, or worse" (p. 1). Negative perceptions of CTE remain, even with changes in CTE that promote students learning more than just career skills (Gordon, 2014). If the goal really is to improve student readiness for both college and careers, "then CTE is an important complement to the standard academic curriculum for more than half of all high school students" (Gray, 2004, p. 129). The integration of quality CTE with academic curriculum helps more students persist in and complete high school (Plank, 2001). 
Findings from a study conducted by Kelly and Price (2009) revealed that students who participate in CTE come into the programs with lower grade-point averages, lower self-esteem, and, for many, a fatalistic perspective on math. Kelly and Price (2009) recommend offering at-risk students an opportunity to start over with reorientation in CTE. CTE programs can result in the betterment and academic re-engagement of students who will likely either fail or drop out without CTE experiences (Kelly \& Price, 2009). Theoretically, both CTE and core-subject teachers recognize that CTE is important for increasing high school students' academic engagement and preparation for postsecondary success. For instance, Shanklin (2014) indicated similarities between perceptions of CTE and core-subject teachers regarding the importance of 21 st-century skill development. Additionally, core-subject teachers recognized the benefit of CTE for students' success in postsecondary employment and education (Shanklin, 2014). However, when core-subject teachers were given the opportunity and assistance to integrate CTE with their subjects, they reverted to the stigmatized position that CTE courses do not prepare students for anything more than lowlevel positions in the workplace and that it is best to keep the two types of curriculum separate from each other (Shanklin, 2014).

Gordon (2014) discussed the elevated perceived value of CTE stemming from educational reform in the late 1980s, which aimed to integrate CTE and standard academic curriculum. Even with brief periods of support for CTE corresponding with educational reform throughout history, core-subject teachers seemingly remain less than enthusiastic about CTE being integrated with standard academic curriculum. California and other states are working to bridge the gap between CTE and core-subject teachers (Turnipseed, 2008). California has been increasing professional development aimed at helping CTE and coresubject teachers work together on integrating CTE and standard academic curriculum. These efforts to integrate CTE and standard academic curriculum show promise; however, without understanding core-subject teachers' perceptions of CTE and the phenomena influencing their perceptions, these efforts are likely in vain.

\section{Background}

This study was purposefully conducted to align with current educational trends in California and ongoing trends seen in the CTE literature. There are three guiding questions for this phenomenological study.

1. What ways do core-subject teachers endorse choices related to career and technical education for all students?

2. Do core-subject teachers encourage students by implementing the idea of career exploration or 4-year university attendance?

3. What are the lived experiences of the participants, and how might these impact their endorsement of CTE?

The assumption that identifying the lived experiences of core-subject 
teachers will help explain their perceptions and endorsement of CTE was supported by the CTE literature. The fact that educators have looked at CTE courses as an option fit only for unmotivated, disinterested students since the beginning of the 20th century has been well documented with a few minor, short-term exceptions. American policymakers continue to find reasons to avoid designing vocational systems that can help students make the transition from secondary school to work (Dougherty, 2016; Schwartz, 2014). According to Stone (2014),

Despite evidence to the contrary, global competitiveness arguments continue to be used as a means of promoting a strictly academic curriculum in high school — one designed solely to prepare students to pursue a fouryear college degree - as the best and only education option. This collegefor-all mentality has had the pernicious effect of diminishing the presence of high school CTE. (p. 4)

The California CTE Pathways Initiative prepares students to succeed in the workforce through partnerships between California Community Colleges and the California Department of Education. These partnerships provide students with seamless CTE from the middle grades through community college (California Community Colleges Chancellor's Office, 2013). In For Each and Every Child: A Strategy for Education Equity and Excellence, the U.S. Department of Education (2013) states:

To achieve the excellence and equity in education on which our future depends, we need a system of American public education that ensures all students have a real and meaningful opportunity to achieve rigorous college- and career-ready standards. A world-class education consists not solely of mastery of core subjects, but also of training in critical thinking and problem-solving, as well as in 21 st-century concerns like global awareness and financial literacy. (p. 12)

\section{Rationale}

The purpose of this research was to understand core-subject teachers' perceptions of CTE and whether they endorsed CTE to students. The study was designed to gather data related to core-subject teachers' perceptions of CTE programs and the level to which teachers actively encourage students to pursue CTE. The secondary purpose was to indicate the phenomena that have influenced core-subject teacher perceptions of CTE. This study was informed by research design literature as well as literature regarding perceptions of CTE, manual arts, industrial arts, and technology education. In the literature, a dichotomy exists between CTE being recognized as valuable and being endorsed by core-subject teachers. Perceptions regarding the value of CTE from the 
literature could best be described as heterogeneous. This seems to indicate that CTE is still struggling to be perceived as a viable option for students.

However, Stone (2014) and others have reported that "after years of languishing as the program for someone else's child, career and technical education (CTE) has been rediscovered by federal, state, and local policymakers" (p. 4).

Over the last two decades, mostly in response to the reform agenda set forth in A Nation at Risk (National Commission on Excellence in Education 1983), high school vocational education in the United States has undergone reconceptualization, the primary change being to make it more compatible with the academic curriculum. (Lewis \& Cheng, 2006, p. 67)

Lynch (2000) indicates that there is not a single statistic, survey, or anecdote that effectively framed the negative public sentiment toward the poor results from American high schools. Lynch (2000) identified A Nation at Risk as having the greatest probability as the seminal event that framed the call for educational reform. When the Carl D. Perkins Vocational and Applied Technology Education Act of 1990 passed, the possibility of change "became an official mandate and challenge for change ... in which the integration of academic and vocational education was set forth as a federal funding guideline" (Lewis \& Cheng, 2006, p. 68).

With the reconceptualization of high school vocational education and its integration with academic education came the "opportunity for the subject to emerge from social isolation in the high school (see especially Gray, 1991; Rosenstock, 1991)" (Lewis \& Cheng, 2006, p. 68). But this was all nearly 30 years ago. Three decades later, CTE is still not perceived positively by teachers, administrators, or the general public. The phenomena that influence teacher perceptions come from long-standing beliefs and actions reinforcing the idea that CTE is a threat to education. More than a century ago, "technical education was called a 'deceptive farce' by zealous guardians of liberal education who considered it as a threat to the intellect and as unacceptable in the public schools" (Gordon, 2014, p. 24). To be clear, the authors value and recognize the benefit of high-quality CTE and have witnessed students become more engaged in their learning as a result of CTE, helping them persist in and complete high school as well as being a catalyst in their success in postsecondary education and careers. This made us wonder why core-subject teachers seem to hold a different perception of CTE.

Creswell and Creswell (2018) explained that exploration is an important reason for conducting qualitative research. They go on to say that "In qualitative research, inquirers use the literature in a manner consistent with the assumptions of learning from the participant" (p. 27). "The researcher seeks to listen to participants and build an understanding based on what is heard" (p. 27). The 
phenomenological design of this study captures the stories of the participants, and the analysis identifies the lived experiences in common that contribute to similar perceptions. The researchers were able to identify themes from transcribed recordings associated with participants' stories. The themes identified were related to participants' perceptions and endorsement of CTE. The study also explores what contributing phenomena have influenced these participants' perceptions of CTE. Exploring individuals' lived experiences collectively can provide a deeper understanding of complex issues like coresubject teachers' perceptions of CTE.

\section{Instrumentation and Data Analysis}

\section{Method}

This phenomenological research investigation of core-subject teacher perceptions was conducted using a survey as well as semistructured, open-ended focus groups and one-on-one interviews. There were two instruments used: the survey and the interview protocol used during the interviews and focus groups. The survey included the following items: (a) the number of years in education, (b) the levels and grades taught and how many years at each level, (c) degree attainment, (d) credentials held, (e) subjects taught, and (f) characteristics used to describe the participants personal connection with CTE, including noneducation-related work experience, parent work experience, partner work experience, or child (or children) work experience in a CTE industry sector and educational attainment for parent, partner, and child (or children) in that sector. The focus groups happened prior to the interviews, which helped further develop the protocol (see Table 1). The protocol developed throughout each focus group and was then used to guide the interviews. However, the interaction during the focus groups and interviews should be considered conversational. The interviewer used verbal and nonverbal feedback to guide and promote the interviewees' storytelling. 
Table 1

Interview Protocol

Question
number Interview question

1.1 Have you discussed options/choices regarding a postsecondary path with your students?

1.2 If yes, what options/choices have you discussed with your students?

1.3 Why did you discuss these options/choices?

1.4 Since you have been reading research that indicates CTE courses in your school meet the levels of rigor and relevance necessary to qualify as to what Bill Daggett, EdD., International Center for Leadership in Education, would you categorize your class as a Quadrant "D" class?

2.1 What is your perception of this information?

2.2 What are your experiences in your life that would cause you to hold that perception?

3.1 You have been asked to collaborate in writing curriculum for your core-subject class, how are you planning to proceed with integrating CTE content standards in the curriculum for your core subject?

3.2 Have you done any work similar to this collaboration?

3.3 If yes, what were the results?

4.1 At your school, from your perspective, based on your experience, what is the postsecondary expectation for students taking your courses?

4.2 At your school, from your perspective, based on your experience, what is the postsecondary expectation for students taking CTE courses?

5.1 How do you feel when one of your students decides to take a CTE course instead of a core-subject course?

5.2 What do you believe are the best choices for students' postsecondary success?

5.3 How do you promote making this choice to your students?

\section{Procedure}

The study was conducted over a 28-week period during the 2018-2019 academic year. The interview protocol was used to gather each participant's perception of CTE. The recorded interviews were transcribed and later coded by a trained coder using perspective themes. The coder was selected based on their 18 years of teaching experience, 5 years of industry experience, and overall 
understanding of CTE. The coder taught middle school language arts, social studies, high school CTE, and had industry-related work experience. All interviews were read multiple times by the coder and researchers, transcribed, coded, and identified themes. All of the focus groups and one-on-one interviews yielded open-ended responses. Initial themes in the coded transcripts were compared to one another to refine themes. While refining the themes, it became evident that participants' responses more accurately belonged in two primary themes: (a) the level of teacher involvement and (b) the perceived level of administrative support.

\section{Participants and Demographics}

Core-subject teachers from a Southern California school district were contacted through their school email addresses and were invited to participate in the study. All participants were high school teachers who held a valid, stateissued, single- or multiple-subject teaching credential. Participation included completion of a survey instrument and either taking part in one of two earlier focus groups or one of nine later one-on-one interviews. There were a total of 16 participants, 11 of whom completed the demographic survey. One focus group had three participants, the other focus group had four participants, and one-onone interviews were conducted with nine participants.

Participants had a total of 258 years of teaching experience $(M=23.45, S D$ $=5.96$ ), with most of this experience at the high school level (Table 2). The majority of the participants held a bachelor's degree in a non-teaching-related CTE industry sector (72.7\%), have before or were still working in a nonteaching-related CTE industry sector (81.8\%), and had at least one parent who spent the majority of their career in a non-teaching-related CTE industry sector (72.7\%; see Table 3). Five of the participants had partners, two of whom were teachers and three of whom worked in another CTE industry sector. Ten of the participants had children, one participant's children were below the age of 9 , two participants children were teachers, and seven of the participants had children working in a non-teaching-related CTE industry sector. 
Table 2

Demographics

\begin{tabular}{|c|c|c|c|c|c|c|c|c|}
\hline \multirow[b]{2}{*}{ Gen. } & \multirow{2}{*}{$\begin{array}{l}\text { Teaching } \\
\text { experience } \\
\text { (years) }\end{array}$} & \multicolumn{4}{|c|}{ Levels (years) } & \multicolumn{2}{|c|}{ Credential } & \multirow[b]{2}{*}{ Subject } \\
\hline & & Ele. & Mid. & Hi. & Coll. & $\begin{array}{l}\text { Sing. } \\
\text { sub. }\end{array}$ & $\begin{array}{l}\text { Multi. } \\
\text { sub. }\end{array}$ & \\
\hline $\mathrm{F}$ & 21 & 10 & & 11 & 5 & $\checkmark$ & $\checkmark$ & Art \\
\hline $\mathrm{F}$ & 25 & & 1 & 24 & & $\checkmark$ & & Math \\
\hline M & 20 & & 2 & 18 & 7 & $\checkmark$ & & English \& ELD \\
\hline M & 28 & & 4 & 24 & & $\checkmark$ & & Soc. Science \\
\hline $\mathrm{F}$ & 30 & & & 30 & & & $\checkmark$ & $\begin{array}{l}\text { English \& } \\
\text { Music }\end{array}$ \\
\hline $\mathrm{F}$ & 25 & & & 25 & & $\checkmark$ & & Soc. Science \\
\hline M & 25 & & 1 & 24 & & & $\checkmark$ & $\begin{array}{l}\text { Math \& } \\
\text { Business }\end{array}$ \\
\hline $\mathrm{F}$ & 16 & & & 16 & & $\checkmark$ & $\checkmark$ & Soc. Science \\
\hline $\mathrm{F}$ & 30 & & 3 & 27 & & $\checkmark$ & & Math \\
\hline M & 11 & & 2 & 9 & & $\checkmark$ & & $\begin{array}{l}\text { Science \& Soc. } \\
\text { Science }\end{array}$ \\
\hline M & 27 & & & 27 & & $\checkmark$ & & English \\
\hline
\end{tabular}

Table 3

Participant Connection with Career and Technical Education

\begin{tabular}{|c|c|c|c|c|c|}
\hline$n$ & $\begin{array}{l}\text { Bachelor's } \\
\text { degree in } \\
\text { CTE } \\
\text { Industry } \\
\text { Sector }\end{array}$ & $\begin{array}{c}\text { Work } \\
\text { Experience in } \\
\text { a CTE } \\
\text { Industry } \\
\text { Sector }\end{array}$ & $\begin{array}{l}\text { Partner } \\
\text { Works in } \\
\text { CTE } \\
\text { Industry } \\
\text { Sector }\end{array}$ & $\begin{array}{c}\text { Parent } \\
\text { Worked in } \\
\text { CTE } \\
\text { Industry } \\
\text { Sector }\end{array}$ & $\begin{array}{l}\text { Children } \\
\text { Work in } \\
\text { CTE } \\
\text { Industry } \\
\text { Sector }\end{array}$ \\
\hline 11 & $8(72.7 \%)$ & $9(81.8 \%)$ & $3(27.3 \%)$ & $8(72.7 \%)$ & $7(63.6 \%)$ \\
\hline
\end{tabular}

Note. CTE industry sectors not including education or teaching.

\section{Phenomena and Themes}

\section{Results}

The presence of phenomena influencing participants' perceptions of CTE became evident during the analysis. There are numerous phenomena that have influenced these participants' perceptions of CTE. Phenomena influencing teacher perception of CTE come from long-standing systematic structures that 
reinforce the idea that CTE only benefits the academically disadvantaged. Perfectionism and the push for external motivators are the two primary phenomena influencing the participants' perceptions. For these participants, numerous lived experiences have abetted their perceptions of CTE. Relating to the white-collar and blue-collar separation is the participants' push for perfectionism. Participants hold a common assumption that student failure (lack of skill and motivation) is a result of parents not pushing their children hard enough. This assumption relinquishes the participants' ability to control what motivates and develops students' abilities. The participants were seemingly uninterested in the potential of their students when the potential is counter to the white-collar societal image. Participants viewed students not attending a 4-year college as a failure, related to their own failures or to their students being incapable. Expressing that anything less than 4-year college enrollment was indicative of failure, participants seemed fixed on the separation of CTE and college. Participants did not express understanding that students could work, earn an associate's degree, and later earn a bachelor's degree. Despite this being more of the norm in Southern California, participants focused on external motivators, such as degrees. The push to put every student in a 4-year college was the focus, more than the student's well-being or ability development. From the analysis, two separate themes emerged: (a) perceived level of administrative support and (b) level of teacher involvement. Several subthemes were identified within the two primary themes. These themes are discussed in the following sections.

\section{Perceived Level of Administrative Support}

This first primary theme connects the perceived actions of school administrators and instances in which they do or do not support CTE programs. Little direct evidence was identified to indicate administrative support for CTE. A participant stated, "I don't think this administration" is trying. "I think [they] tried [minimally] last year" to develop scheduling that allows students to be successful academically and in CTE. There is a level of misunderstanding that participants have surrounding CTE. Most participants believed that taking CTE classes precludes students from attending college. Participants believed that administrators actively encourage students to pursue one or the other, CTE or a 4-year university. One participant stated that "all the way, federal, state, all the way down to our administration, all the way down to our faculty meetings that everything is college-prep, college-ready, A through G" (A-G is in reference to the University of California's entrance requirements). The participants expressed experiencing pressure to increase college entrance and inflate grades from the administration. Another participant was concerned that "IB (International Baccalaureate), AP (Advanced Placement), and CTE can't be simultaneously supported." They stated, "We offer a variety of programs," and "while I am a proponent of IB and AP," we can't "support [too much variety]." 
Related to simultaneously supporting programs, participants discussed unequal programmatic funding.

The participants discussed the seemingly larger amounts of funding for CTE programs and inadequate funding for academic programs. Apparently, the administration had not been transparent about the funding or funding structures at the school, district, county, or state levels. The participants did not have a way to compare CTE and academic classroom operating costs. Participants expressed feeling threatened or undervalued by the higher amounts of money allocated to CTE. Participants expressed frustration with the lack of explanation for CTE funding compared to funding and support associated with opportunities for professional growth and collaboration with other educators. The participants seemingly had a negative perception of CTE due to the perceived additional support, especially related to funding, that the administration gave CTE.

Participants reported the interest that administrators have in how teachers are performing and related that to adequate program funding and interdepartmental training for the teachers. Participants recognized the existence of a dichotomy between what the administrators say they support and what their actions indicate. Policies that prevent CTE programs from continuing to be the place to put "unplaceable" students are often ignored in the name of just getting students in a class. A participant refers to the importance of ignoring these policies when stating, "CTE helps students figure out what they want to do as a career, [CTE programs] give [students] guidance. I think those programs give meaning and purpose to students; they give them a place of belonging and excitement." The participant added, "I think overall, I would completely support CTE, or I do support CTE, but conversely, I fully support going to a 4-year university." Another participant reflected on the issue of rigor, stating that "the students are not willing to adjust" to meet teacher expectations. "Now, if you get a higher academic student in the CTE classes, they know how to meet a teacher's expectations, but again CTE is not being funneled those students, so you just have to keep dumbing it down. CTE classes [can't be] rigorous because students are not high achievers."

\section{Level of Teacher Involvement}

The second primary theme presents examples of the teachers' desire to guide and direct their students' postsecondary choices but not endorse CTE. Participants stated that they support CTE; however, their stated actions do not show support for CTE. Participants are passionate about the academic advantages that AVID and IB programs provide. Participants seemed to lack an understanding of and enthusiasm for CTE. Participants downplayed discussions related to pursuing employment, certificate programs, trade schools, and other experiences commonly associated with CTE while at the same time emphasizing the importance of attending a 4-year university and earning a bachelor's degree. The data analysis revealed that the participants disapproved of students enrolled 
in a CTE program, likely resulting in these students receiving less career and academic guidance when compared with students pursuing a purely academic schedule.

Participants discussed factors that would positively influence their perception of CTE. A participant stated, "I'm a huge proponent of CTE when it is done right." When asked how they would define "done right," the participant stated, "I would say being done right is that there's not a stigma attached to it." Following the discussion regarding stigma, the participant presents a stigmatized perception of CTE, saying, "the level of quality of education for all students whether it's CP (college prep), AP, or IB is important." Only low achieving "students [are] buoyed up by CTE and are then more successful." Another participant stated, "I do believe that CTE is viable, and it should be a choice"; "not everyone is going to college." Another participant reported, "I'm proud to be a part of this school that has these programs; I know Culinary exists, I know that people have benefitted from it; I know that people do learn a lot and go out and use these skills; when I hear about that someone's in them, I say, good for you, the more, the better." Later this participant stated that "all of my students will attend college." Similarly, all participants verbalized their support for CTE in general while almost simultaneously countering that support by presenting a dichotomy in which CTE is lesser-than, only for low achieving students, and that all their students were attending a 4-year university. The researchers expected the participants to have a negative perception of CTE; however, they were surprised when reviewing the transcripts to see that participants knew little about CTE and held beliefs about CTE based on limited anecdotal evidence.

\section{Implications}

The data collected related to the guiding questions indicated that participants were positively disposed to the idea of CTE; however, they primarily focused on encouraging their students to attend a 4-year college, as if that is the only option. This is despite their own personal connections to CTE. The participants did not enthusiastically endorse the decision to pursue a career through CTE programs. Participants presented the idea of career planning as less important and separate from obtaining a 4-year college degree. The participants were sincere, student-centered educators who not only spend their contract hours but their own personal time investigating instructional strategies and getting to know the thoughts, dreams, and turmoil within their students' lives; however, these apparent facts make the participants' resistance to unequivocally recommend $\mathrm{CTE}$ as an option much more difficult for the researchers to reconcile. If teachers, like the participants, are willing to learn about CTE options at their school but are not willing to endorse them, it seems even less likely that individuals not willing to learn about CTE options will support CTE.

For more than 30 years, it has been said that individuals who were less likely to choose postsecondary education as their first choice after high school 
were underachievers and not competent enough to successfully attend postsecondary institutions. However, Berliner and Biddle (1996) argue that "the negative effects of vocational education may be likely because of not enough time in the schedule" to balance CTE and academic courses (p. 2). The limited ability for CTE students to take "academic courses can be the explanation for an achievement gap; not the fact that students took vocational education classes" (p. 2). This issue was addressed by a participant, "I think administration probably figures CTE is not for academic kids." The participants' school site course schedule limited students' ability to take both academic and CTE course offerings. At the beginning of the 20th century, CTE was founded on the idea of integrating apprenticeships with classroom instruction as part of the public schools' curriculum. Despite the well-intentioned plans to increase student enrollment in CTE and place students in a position to develop both academic and industry skills, technological literacy, and 21 st-century skills before entering postsecondary schooling or career, CTE became the easiest place to put underachievers. The educational system in the United States decided to separate work-based learning from academics, which engendered the belief that CTE was only valuable for those students who placed little value on learning. By continuing to ignore the value inherent in CTE, educators in the United States are withholding the key to best practices for many students, especially with respect to postsecondary success.

\section{Recommendations for Educational Leaders Including Teachers}

Four-year college attendance should not be the only goal. The phenomenon of only promoting 4-year college discounts the value of learning a skilled trade. Comparing the graduation rate at CSUSB for first-time students at $57 \%$ after 6 years and community college transfer students at $72 \%$ after 6 years, the data supports the notion that students should attend a community college and learn a skilled trade prior to attending the University (California State University, San Bernardino, 2018). One recommendation to educational leaders is to recognize the intrinsic value of CTE, to acknowledge that, for many, it represents equivalent training that can reengage students and promote postsecondary success. Another recommendation for educational leaders is to provide enough time in the school year for students to try different CTE programs without missing important academic courses. Students should have options and not be forced to decide between academics and CTE. Students should not be deciding at 15 years old about pursuing either postsecondary schooling or work.

Teachers often work in semi-isolated environments. Being separated from other faculty does not encourage a strong sense of community among the faculty members. This individualistic nature of the teaching profession limits the time that could be used to develop integrated curriculum. A third recommendation for educational leaders is to provide time that can be used for communication and collaboration to design integrated academic and CTE curriculum. 
Administrators should be also more transparent about scheduling and funding. California is already pushing for college and career readiness through efforts like Linked Learning, but more time for integration efforts is needed.

\section{Conclusions}

Pushing attendance to a 4-year college is not working for many people, and college attendance should not be presented as the only option. Balancing academic and CTE course offerings will provide the next generation of students with the technological literacy and 21st-century skills that they are going to need. Instead of directing our graduates to college before they have a goal or direction in mind, we should be encouraging more career planning and exploration. Students can receive work experience and on the job training as well as further develop career skills while they explore career and school options. Students might find a career that suits them, or at least, they will learn more about themselves and their interests before committing to expensive postsecondary schooling. This sort of discussion always reminds us of a story our late friend John Marcus would tell. John had just finished an undergraduate degree in zoology and premed. John would remind us that at this point, he had spent 17 of his 21 years of life in school. At his first interview for a summer job, the interviewer asked him, "What is it that you can do?" John responded, "Nothing, I've been in school all of my life." John later went on to become a successful attorney and loved every day of work. The somewhat sad reality of the story is that without CTE experiences, students graduate every year with little to no practical skills, resulting in little postsecondary direction and no way to support themselves while exploring their options.

\section{References}

Bae, S., \& Darling-Hammond, L. (2014). Recognizing college and career readiness in the California school accountability system. Stanford, CA: Stanford Center for Opportunity Policy in Education. Retrieved from https://edpolicy.stanford.edu/library/publications/1279

Bartholomew, S. (2014). Why we cannot afford to lose CTE in schools. International Journal of Vocational and Technical Education, 6(2), 7-12. Retrieved from https://academicjournals.org/journal/IJVTE/article-full-textpdf/117759047503

Berliner, D., \& Biddle, B. (1996). In defense of schools. Vocational Education Journal, 71(3), 36-38.

Brand, B., Valent, A., \& Browning, A. (2013). How career and technical education can help students be college and career ready: A primer. Washington, DC: College and Career Readiness and Success Center, American Institutes for Research. Retrieved from https://ccrscenter.org/products-resources/how-career-and-technicaleducation-can-help-students-be-college-and-career-ready 
California Community Colleges Chancellor's Office. (2013). Career Technical Education Pathways Initiative. Sacramento, CA: Author. Retrieved from https://www.wested.org/wpcontent/uploads/2016/11/1379440350CTEPathwaysInitiativeReport-3.pdf

California State University, San Bernardino. (2018). Facts and stats: Fall 2018 stats. Retrieved May 20, 2019, from https://www.csusb.edu/aboutcsusb/facts-and-stats

Carl D. Perkins Vocational and Applied Technology Education Act of 1990, Pub. L. No. 105-332 (1990).

Creswell, J. W., \& Creswell, J. D. (2018). Research design: Qualitative, quantitative, and mixed methods approaches. Thousand Oaks, CA: Sage.

Dougherty, S. M. (2016). Career and technical education in high school: Does it improve student outcomes? Washington, DC: Thomas B. Fordham Institute. Retrieved from https://fordhaminstitute.org/national/research/career-and-technicaleducation-high-school-does-it-improve-student-outcomes

Gordon, H. R. D. (2014). The history and growth of career and technical education in America (4th ed.). Long Grove, IL: Waveland Press.

Gray, K. (2004). Is high school career and technical education obsolete? Phi Delta Kappan, 86(2), 128-134. doi:10.1177/003172170408600209

Kelly, S., \& Price, H. (2009). Vocational education: A clean slate for disengaged students? Social Science Research, 38(4), 810-825. doi:10.1016/j.ssresearch.2009.05.002

Lewis, S., and Cheng, S.-Y. (2006). Tracking, expectations, and the transformation of vocational education. American Journal of Education, 113(1), 67-99. doi:10.1086/506494

Lynch, R. L. (2000). High school career and technical education for the first decade of the 21st century. Journal of Vocational Education Research, 25(2), 155-198.

Plank, S. B. (2001). A question of balance: CTE, academic courses, high school persistence, and student achievement. Journal of Vocational Education Research, 26(3), 279-327. doi:10.5328/JVER26.3.279

Plank, S. B., DeLuca, S., \& Estacion, A. (2008). High school dropout and the role of career and technical education: A survival analysis of surviving high school. Sociology of Education, 81(3), 345-370. doi:10.1177/003804070808100402

Shanklin, S. L. (2014). Educators' perceptions and value of career and technical education programs (Doctoral dissertation). Available from ProQuest Dissertations and Theses database. (UMI No. 3613539)

Stone, J. R., III (2014). More than one way: The case for high-quality CTE. American Educator, 38(3), 4-11, 39. Retrieved from https://www.aft.org/sites/default/files/stone.pdf 
Schwartz, R. B. (2014). The pursuit of pathways: Combining rigorous academics with career training. American Educator, 38(3), 24-29, 41. Retrieved from https://www.aft.org/sites/default/files/schwartz.pdf

Tucker, S. L. (2019). Perception influenced by phenomena: Identify core-subject teacher perceptions of career technical education (Doctoral dissertation, California State University, San Bernardino). Retrieved from https://scholarworks.lib.csusb.edu/etd/874

Turnipseed, B. Y. (2008). Teachers' perceptions of integrating academics and career and technical education across the curriculum (Doctoral dissertation). Available from ProQuest Dissertations and Theses database. (UMI No. 3337368)

U.S. Department of Education. (2013). For each and every child: A strategy for education equity and excellence. Washington, DC: Author. Retrieved from https://www2.ed.gov/about/bdscomm/list/eec/equity-excellencecommission-report.pdf

Wonacott, M. E. (2003). History and evolution of vocational and careertechnical education. A compilation. Columbus: Center on Education and Training for Employment, College of Education, The Ohio State University. Retrieved from https://www.calpro-online.org/eric/docs/compilationhistory.pdf

\footnotetext{
About the Authors

Sheri L. Tucker (sheriltucker@gmail.com) is a Career and Technical Education Teacher in the Hospitality, Tourism, and Recreation industry sector, Food Service and Hospitality Pathway at La Quinta High School.
}

Andrew J. Hughes (andrew.hughes@csusb.edu) is Assistant Professor in the Career and Technical Education Program at California State University San Bernardino. 